\title{
Interstitial Transpedal MR-Lymphangiography of Central Lymphatics Using a Standard MR Contrast Agent: Feasibility and Initial Results in Patients with Chylous Effusions
}

\author{
Interstitielle transpedale MR-Lymphangiografie zentraler \\ Lymphbahnen mit einem Standard-MRT-Kontrastmittel: \\ Machbarkeit und erste Ergebnisse bei Patienten mit chylösen \\ Ergüssen
}

Authors

Claus Christian Pieper, Hans Heinz Schild

Affiliation

Department of Radiology, University of Bonn, Germany

Key words

lymphatic, lymphography, thorax, MR imaging

received 25.07.2017

accepted 15.03.2018

\section{Bibliography \\ DOI https://doi.org/10.1055/a-0598-5063 \\ Published online: 17.4 .2018 \\ Fortschr Röntgenstr 2018; 190: 938-945 \\ (c) Georg Thieme Verlag KG, Stuttgart · New York \\ ISSN 1438-9029}

Correspondence

Priv.-Doz. Dr. Claus Christian Pieper

Radiologische Klinik, Universitätsklinik Bonn,

Sigmund-Freud-Str. 25, 53105 Bonn, Germany

Tel.: ++ 49/2 28/28715237

Fax: $++49 / 2$ 28/28719083

claus.christian.pieper@ukb.uni-bonn.de

\section{ZUSAMMENFASSUNG}

Ziel Beschreibung einer neuen Technik der transpedalen Magnetresonanzlymphangiografie (tMRL) mittels interstitieller Injektion eines gadoliniumhaltigen Standardkontrastmittels zur Visualisierung des zentralen Lymphsystems bei Patienten mit chylösen Ergüssen.

Material und Methoden Erste Erfahrungen mit der tMRL bei sieben aufeinanderfolgenden Patienten mit chylösen Ergüssen wurden retrospektiv ausgewertet. Es wurde eine hochaufgelöste dreidimensionale Multiecho (mDIXON) Sequenz verwendet, um den gesamten Torso der Patienten vor und nach interstitieller pedaler Injektion eines regulären extrazellulären gadoliniumhaltigen Kontrastmittels abzubilden. Die MRT-Untersuchungen wurden von zwei Radiologen qualitativ hinsichtlich Darstellung der zentralen (abdominellen und thorakalen) Lymphbahnen, deren Anatomie sowie hinsichtlich einer lymphatischen Pathologie (chylolymphatische Leckage oder Reflux) analysiert.

Ergebnisse Die tMRL war in 6/7 Patienten technisch erfolgreich und zeigte eine chylolymphatische Leckage in 3/7 Fällen, eine lymphatische Malformation in 1/7 Fällen, einen chylolymphatischen Reflux in 1/7 Fällen sowie regelrechten chylolymphatischen Fluss in den zentralen Lymphbahnen in 1/7 Fällen. Bei einem Patienten wurde weder eine Kontrastierung zentraler Lymphbahnen, noch eine Leckage beobachtet. Die Ergebnisse der tMRL waren prospektiv in allen technisch erfolgreichen Fällen hilfreich zur Planung der weiteren Therapie und beeinflussten diese in vier Fällen erheblich. Alle Untersuchungen wurden von den Patienten gut toleriert ohne Auftreten von Komplikationen. Eine Allgemeinanästhesie oder Sedierung war nicht erforderlich.

Schlussfolgerung Die transpedale MR-Lymphangiografie mit interstitieller Injektion eines regulären extrazellulären gadoliniumhaltigen Kontrastmittels ist ohne Allgemeinanästhesie in der klinischen Routine durchführbar und erlaubt die Beurteilung von Pathologien des zentralen Lymphsystems.

\section{Kernaussagen}

- Eine transpedale Kontrastierung zentraler Lymphbahnen in der MRT ist technisch machbar.

- Hierzu kann reguläres extrazelluläres gadoliniumhaltiges Kontrastmittel verwendet werden.

- Anatomie und pathologische Veränderungen zentraler Lymphbahnen können mittels MR-Lymphangiografie evaluiert werden.

- Die transpedale MR-Lymphangiografie ist hilfreich zur Therapieplanung von chylösen Ergüssen.

\section{ABSTRACT}

Purpose To describe a novel technique for transpedal magnetic resonance lymphangiography (tMRL) with interstitial injection of a standard gadolinium-based contrast agent, and to assess its ability to visualize the central lymphatic system (CLS) in patients with chylous effusions. 
Materials and Methods Experiences with TMRL were retrospectively reviewed in seven patients with chylous effusions. High-resolution three-dimensional multi-echo (mDIXON) images of the entire torso were obtained before and after interstitial injection of an extracellular gadolinium-based contrast agent. MR examinations were assessed qualitatively by two radiologists with respect to visualization of central lymphatics, delineation of their anatomy and presence of a lymphatic pathology (chylolymphatic leakage or reflux).

Results Examination was technically successful in 6/7 patients. TMRL confirmed the location of chylolymphatic leakage in $3 / 7$, demonstrated a lymphatic malformation in $1 / 7$, chylolymphatic reflux in $1 / 7$, and confirmed normal chylolymphatic flow in the central lymphatics in $1 / 7$ patients. In one patient neither CLS enhancement nor leakage were detectable. tMRL findings were considered helpful in all technically successful cases, and considerably influenced further treatment in four patients. All examinations were well tolerated without complications. No general anesthesia or conscious sedation was necessary.
Conclusion Transpedal MR-lymphangiography with interstitial injection of a standard extracellular gadolinium-based contrast agent is feasible in clinical routine without general anesthesia and allows for assessment of pathologic conditions of central lymphatics.

\section{Key Points}

- Transpedal MR-lymphangiography of central lymphatics is technically feasible.

- A standard extracellular gadolinium-based contrast agent can be used for tMRL.

- tMRL allows for evaluation of anatomy and pathologies of central lymphatics.

- tMRL is a useful tool for treatment planning in chylous effusions.

\section{Citation Format}

- Pieper CC, Schild HH. Interstitial Transpedal MR-Lymphangiography of Central Lymphatics Using a Standard MR Contrast Agent: Feasibility and Initial Results in Patients with Chylous Effusions. Fortschr Röntgenstr 2018; 190: 938-945

\section{Introduction}

Intractable chylous effusions are associated with considerable morbidity and mortality [1, 2]. One of the main problems, especially in minimally invasive treatment of lymphatic pathologies [2-5] is the lack of simple imaging techniques for the visualization of the central lymphatic system (CLS; i. e., cisterna chyli (CCh), thoracic duct (TD) and direct tributaries) [6].

There are certain disadvantages associated with existing CLS imaging approaches. Conventional X-ray lymphangiography is technically challenging, invasive and time-consuming [7]. Lymphoscintigraphy has insufficient anatomical resolution for CLS evaluation [7]. On non-contrast MR-lymphangiography, central lymphatics can be evaluated, but it can be difficult to distinguish lymphatics from surrounding tissue [7, 8]. Dynamic contrast-enhanced MR-lymphangiography is a promising new approach $[9,10]$. However, it is time-consuming due to necessary sonographically guided lymph node puncture outside the scanner room, and usually requires general anesthesia or at least sedation.

To overcome these disadvantages, we sought to develop an MR imaging technique that can provide information on CLS anatomy, without time-consuming intranodal contrast application or general anesthesia. The aim of this study is to describe this new technique for transpedal MR-lymphangiography (tMRL) with interstitial injection of a standard gadolinium-based contrast agent and to assess its ability to visualize the CLS in patients with chylous effusions.

\section{Materials and Methods}

We retrospectively reviewed our recent experiences (10/201504/16) with tMRL to visualize the central lymphatics in seven patients referred to our institution for the treatment of clinically proven therapy-resistant chylous effusions. Patient characteristics and procedural information are given in case studies in the results section. Institutional review board approval and the patients' written informed consent for the procedure and for data analysis were obtained.

MR imaging was performed by the same radiologist (C.C.P. with more than 5 years of experience) on a 1.5 Tesla MR scanner (Ingenia, Philips Healthcare, Best, The Netherlands) with the patient in a supine position. A leg wedge was not used to allow for free lymph flow. Patients were neither sedated nor intubated. A 16-channel phased-array coil was used to cover the entire torso. After preparation of both feet for aseptic injection, local anesthesia was administered with $0.2 \mathrm{ml}$ mepivacaine $1 \%$ (Mecain, Actavis, Langenfeld, Germany) per interdigital space using a 27-gauge needle. $6 \mathrm{ml}$ of $1.0 \mathrm{mmol} / \mathrm{ml}$ gadobutrol (Gadovist, Bayer Vital, Leverkusen, Germany) were diluted with saline solution to $8 \mathrm{ml}$ to increase the volume for injection.

An axial non-contrast breath-hold three-dimensional T1weighted multi-gradient echo (mDIXON) sequence was acquired [11] ( $\triangleright$ Table 1 ). Three separate stacks of axial slices were sufficient to cover the entire torso.

Thereafter, bilateral interstitial intradermal injection of $1 \mathrm{ml}$ of the diluted contrast medium per interdigital space was performed (overall $8 \mathrm{ml}$ of $6.0 \mathrm{mmol}$ gadobutrol which is the recommended standard dose for intravenous application in patients with a bodyweight of $60 \mathrm{~kg}$ ). The patients were asked to move their legs for 3-5 minutes. The three-dimensional mDIXON sequence was then repeated every 5 minutes to observe lymphatic flow until washout and renal contrast medium excretion were observed. The time a patient remained in the scanner was documented.

MR examinations were assessed qualitatively by two radiologists (C.C.P. and H.H.S.). Visualization of the central lymphatics (excellent, moderate, poor, not visible), delineation of their anat- 
- Table 1 Imaging parameters.

- Tab. 1 Sequenzparameter.

\begin{tabular}{|l|l|}
\hline Repetition time & Shortest \\
\hline Echo time & $1.8 \mathrm{~ms}$ and $4 \mathrm{~ms}$ \\
\hline Flip angle & $15^{\circ}$ \\
\hline k-space acquisition & Cartesian \\
\hline Field of view & $300 \times 400 \mathrm{~mm}$ \\
\hline Acquired voxel size & $1 \times 1.2 \times 2.5 \mathrm{~mm}^{3}$ \\
\hline Reconstructed voxel size & $1 \times 1 \times 1 \mathrm{~mm}^{3}$ \\
\hline Parallel imaging factor & 1.65 \\
\hline Acquisition time per stack & 10 seconds \\
\hline
\end{tabular}

omy and the presence of chylolymphatic leakage or reflux were evaluated. Leakage was defined as progressive pooling of contrast medium outside of lymphatic structures, reflux as retrograde contrast medium flow within lymphatic channels. Technical success was defined as excellent or moderate visualization of the CLS (especially of the TD, as a CCh can be anatomically absent in up to $30 \%$ of cases [12]) or detection of pathology preventing contrast flow into the CLS. Venous contrast contamination obscuring the lymphatics was assessed. Diagnosis of lymphatic pathology and impact of tMRL on patient management were determined in consensus by both radiologists. The time for visualization of different parts of the lymphatic system was recorded. Any adverse events associated with tMRL were noted.

\section{Results}

\section{Case studies}

Patient 1

A 24-year-old patient presented with left-sided non-traumatic chylothorax. Thoracoscopic surgery and parenteral nutrition had been unsuccessful with persisting leakage of $1000 \mathrm{ml} /$ day. On tMRL the pelvic and retroperitoneal lymphatics, CCh and the lower two-thirds of the TD appeared normal with segmental TD duplication in the lower thorax. Abnormally dilated lymphatic ducts surrounded the left-sided termination of the TD ( $\bullet$ Fig. 1). Chylolymphatic leakage or reflux was not observed. A diagnosis of localized lymphatic malformation as the cause of the chylothorax was established and confirmed by conventional lymphangiography during the subsequent lymphatic intervention. After transabdominal embolization of the malformation, drainage via the chest tube ceased immediately.

\section{Patient 2}

A 54-year-old patient suffering from necrotizing pancreatitis with left subclavian vein thrombosis developed bilateral chylothorax, chylopericardium and chylous ascites that were refractory to conservative treatment. TD ligation, pleurectomy and irradiation of the TD had been unsuccessful. Lymphoscintigraphy was reported to show normal tracer flow without depiction of pathology.

On tMRL contrast medium flow was unobstructed. The CLS appeared normal with segmental duplications of the TD in the mid and upper thorax. There was extensive chylolymphatic reflux from the cervical part of the TD into dilated mediastinal, pericardial and bronchial lymphatics ( $\triangleright$ Fig. 2). Leakage was not identified. Reflux was confirmed by intranodal lymphangiography. After TD embolization, drainage via bilateral chest tubes and an ascites drain ceased within three days. The chylopericardium also decreased on follow-up imaging.

\section{Patient 3}

A 78-year-old patient developed chylous ascites refractory to conservative treatment after surgical abdominal aortic aneurysm repair. tMRL demonstrated normal pelvic lymphatics. At the bifurcation of the aortic graft, contrast medium leaked into a small retroaortic recess which communicated with the peritoneal cavity. Intranodal oily lymphangiography was performed with continuation of parenteral nutrition. After one week the leakage resolved and did not recur during follow-up of 15 months under full oral nutrition.

\section{Patient 4}

A 62-year-old patient developed a left-sided chylothorax after surgery for recurrent pleural mesothelioma. Parenteral nutrition with somatostatin application and several attempts of TD ligation and pleurodesis were unsuccessful. tMRL demonstrated unobstructed lymph flow without reflux. Several tortuous lymphatic channels in the middle and upper thorax coalesced into a single TD before its termination. Retrocardially the tortuous lymphatic channels showed contrast leakage into the left pleural cavity ( $\triangleright$ Fig. 3). Intranodal lymphangiography confirmed the diagnosis of postoperative leakage of three lymphatic channels. Leakage ceased immediately after successful TD embolization.

\section{Patient 5}

A 58-year-old patient suffered from a right-sided chylothorax after esophagectomy with gastric interposition for esophageal cancer. Chest tube drainage did not drop below $1000 \mathrm{ml}$ per day under total parenteral nutrition. tMRL was performed to assess lymphatic anatomy which can be altered after gastric interposition surgery. The retroperitoneal lymphatics, the CCh and the lower part of the TD appeared normal. Contrast medium extravasation from a side branch of the TD was visible retrocardially ( $\triangleright$ Fig. 4). Importantly tMRL demonstrated an additional retroaortic lymphatic channel receiving lymph flow from the retroperitoneal lymphatics not draining into the CCh. This channel drained into the TD immediately below the leakage. During embolization special care was taken to occlude this channel and the leakage site itself to prevent further chylolymphatic flow towards the leak. Leakage ceased immediately after intervention. 

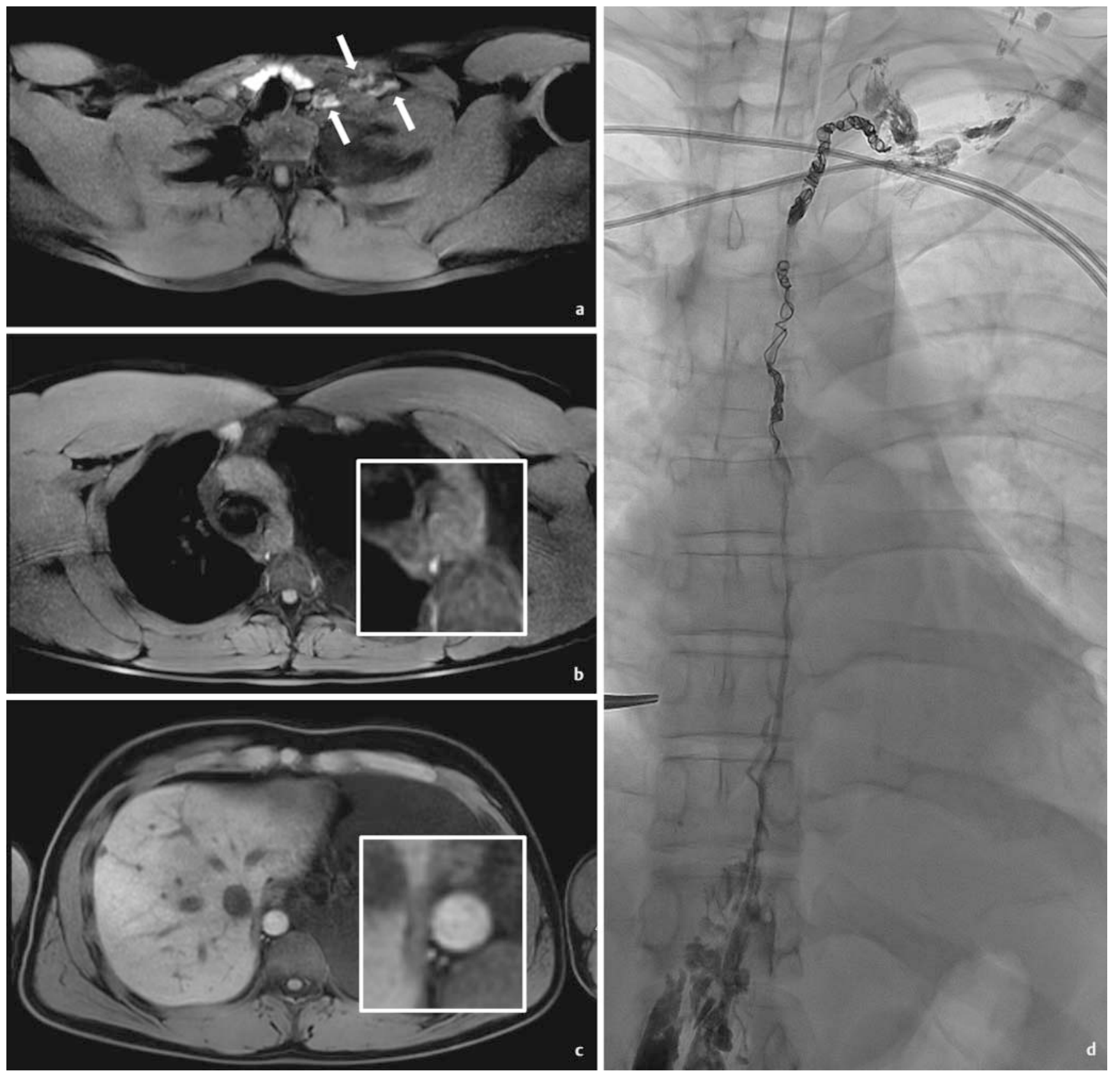

- Fig. 1 Case study 1. a-c Axial tMRL images in a patient with extensive left-sided chylothorax with mediastinal shift to the right. Examination showed normal thoracic lymphatic anatomy with duplication of the thoracic duct in the lower thorax (inset magnification in c) and dilated leftsided lymphatics surrounding the termination of the TD (arrows). Due to the employed imaging technique, the thyroid gland appears hyperintense in $\mathbf{a}$. This does not reflect contrast enhancement. $\mathbf{d}$ Posterior-anterior intra-interventional image after transabdominal embolization showing the left periclavicular lymphatic malformation (arrows). The duplication of the TD in the lower thorax is partially obscured by mild contrast medium leakage from the puncture site.

- Abb. 1 Fallstudie 1. a-c Axiale tMRL-Bilder eines Patienten mit ausgedehntem linksseitigem Chylothorax mit Mediastinalshift nach rechts. Die Untersuchung zeigt normale anatomische Verhältnisse der thorakalen Lymphbahnen mit Duplikation des Ductus thoracicus im unteren Thoraxdrittel (Vergrößerung in c) sowie dilatierte Lymphgefäße im Bereich der Mündung des Ductus thoracicus im linken Venenwinkel (Pfeile). Technisch bedingt kommt die Schilddrüse in a hyperintens zur Darstellung. Dies ist kein Ausdruck einer Kontrastmittelaufnahme. d Intrainterventionelle posterior-anterior Aufnahme nach transabdomineller Embolisation mit Nachweis der links periklavikulären lymphatischen Malformation (Pfeile). Die Duplikation des Ductus thoracicus im unteren Thoraxdrittel ist partiell durch einen geringen Kontrastmittelaustritt aus der Punktionsstelle überlagert. 

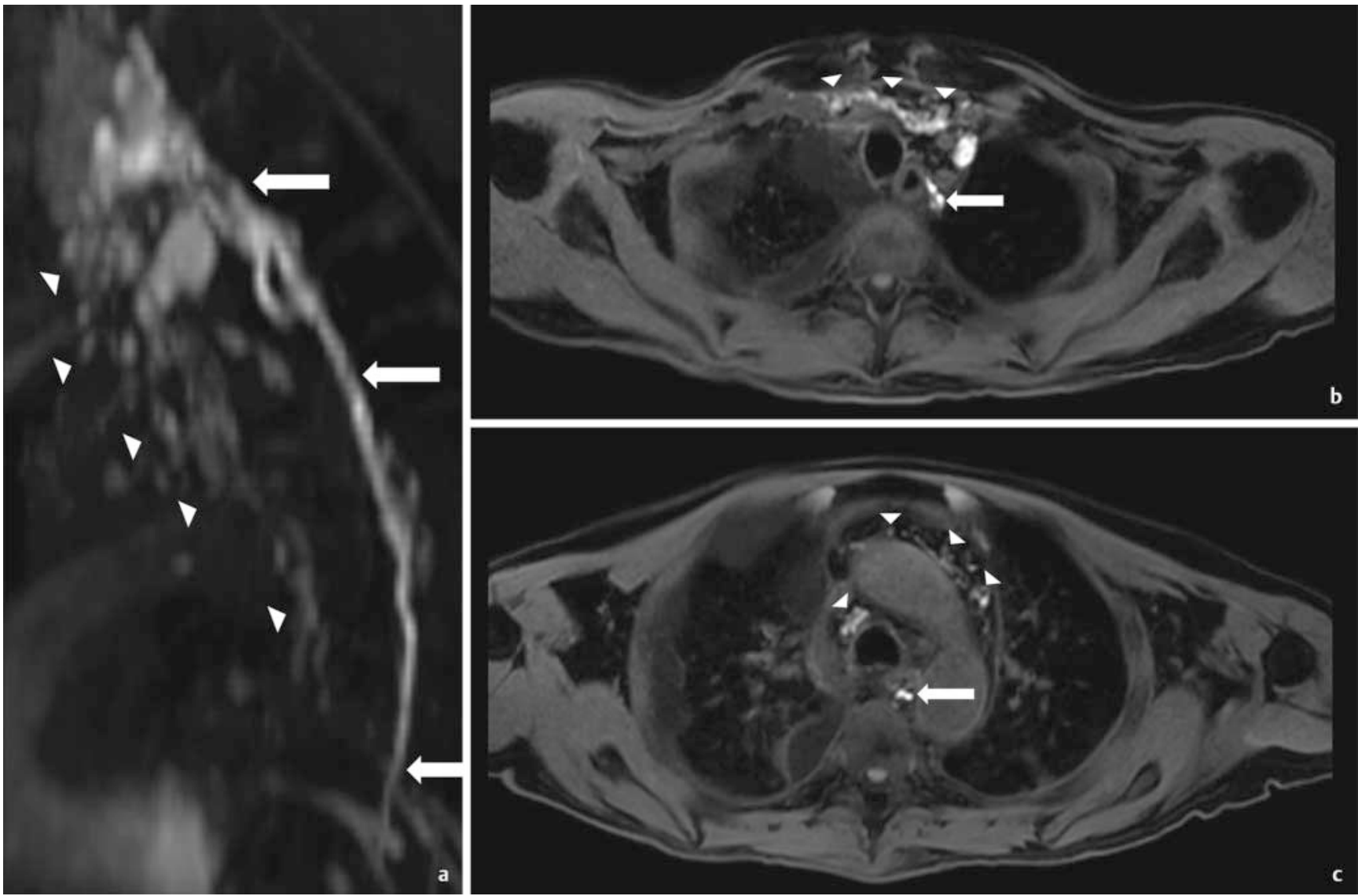

- Fig. 2 Case study 2. Sagittal maximum intensity projection a and axial slices b, $\mathbf{c}$ of a tMRL examination in a patient with bilateral chylothorax, chylopericardium and chylous ascites showing extensive chylolymphatic reflux from the cervical part of the thoracic duct (arrows) into the mediastinal, bronchial, pulmonary and pericardial lymphatics (arrow heads).

- Abb. 2 Fallstudie 2. Sagittale Maximum Intensity Projection a und axiale Schichten b, c der tMRL-Untersuchung eines Patienten mit bilateralem Chylothorax, Chyloperikard und Chylaszites. Die Untersuchung zeigt einen ausgedehnten chylolymphatischen Reflux ausgehend vom zervikalen Anteil des Ductus thoracicus (Pfeile) in mediastinale, bronchiale, pulmonale und perikardiale Lymphbahnen (Pfeilspitzen).

\section{Patient 6}

A 54-year-old patient presented with chylous ascites refractory to conservative treatment after radical peritonectomy and hyperthermic intraperitoneal chemotherapy for peritoneal metastases of colorectal cancer (1500 ml per day). tMRL showed prompt contrast enhancement of the pelvic lymphatics while the retroperitoneal lymphatics showed only minimal enhancement. The CLS and a leakage site could not be identified. Intranodal oily lymphangiography initially demonstrated venous drainage of contrast medium due to inguinal lymphovenous anastomoses. After additional pelvic lymph node punctures, contrast agent ascended into the retroperitoneal lymphatics demonstrating diffuse leakage into the peritoneal cavity. As in TMRL the CLS did not show any enhancement. Leakage ultimately resolved under parenteral nutrition two weeks after lymphangiography.

\section{Patient 7}

A 72-year-old female patient with a history of lymphoma currently in partial remission after radiochemotherapy presented with a right-sided chylothorax unresponsive to conservative treatment.
tMRL demonstrated unobstructed lymph flow without reflux. The CLS appeared normal without leakage. There was residual lymphoma in the upper retroperitoneum surrounding the CCh not showing contrast enhancement. Based on these findings, a lymphatic intervention was not indicated. Continuation of conservative treatment ultimately was successful without recurrence of the chylothorax.

\section{Overall imaging results}

Interstitial tMRL was technically successful in 6/7 patients with visualization of the CLS rated as excellent in 5/7 and good in 1/7 patients. TMRL confirmed the location of leakage in 3/7, demonstrated a lymphatic malformation in $1 / 7$, reflux in $1 / 7$ and confirmed normal chylolymphatic flow in the central lymphatics in 1/7 patients. In patient 6 neither CLS enhancement nor leakage was detectable.

In technically successful cases, contrast medium was detectable in the central lymphatics on initial images acquired after contrast injection. Image acquisition was performed for at least 20 min after contrast injection (at least 5 repetitions of the $3 \mathrm{D}$ $\mathrm{T} 1 \mathrm{w}$-sequence). The median time a patient was in the scanner 


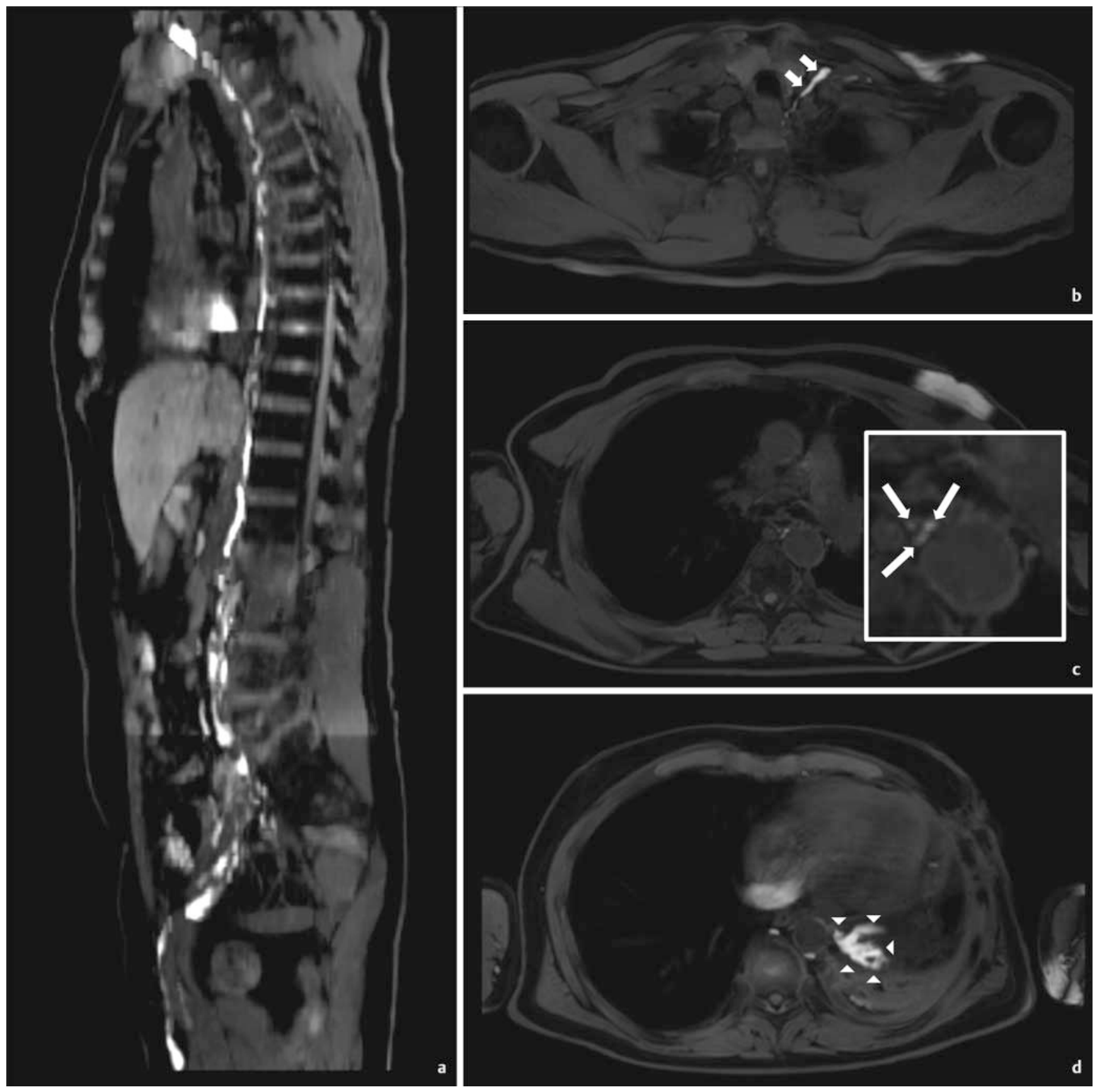

- Fig. 3 Case study 4. Multiplanar reconstruction a and axial slices $\mathbf{b}$ - $\mathbf{d}$ of tMRL demonstrates several tortuous lymphatic channels in the middle to upper thorax (arrow) with postoperative chylous leakage (arrow heads) with left-sided chylothorax. Singular thoracic duct before its termination (short arrows).

- Abb. 3 Fallstudie 4. Multiplanare Rekonstruktion a und axiale Bilder $\mathbf{b}$ - d einer tMRL mit mehreren geschlängelt verlaufenden Lymphbahnen im mittleren und oberen Thoraxdrittel (Pfeile) und postoperativer chylöser Leckage (Pfeilspitzen) mit linksseitigem Chylothorax. Singulärer Ductus thoracicus vor seiner Mündung im linken Venenwinkel (kurze Pfeile).

for contrast-enhanced MRL (including preparation, pre-injection T1-images, contrast injection and post-contrast T1-images) was 48 min (range $37-61 \mathrm{~min}$ ). Contrast medium washout was observed within 15 to 25 minutes after initial post-contrast images. Although contrast medium was also already present within the renal pelvis on initial images, relevant venous contamination was not observed.
tMRL findings were considered helpful in all technically successful cases, and considerably influenced further treatment in four patients. In patient 2 suffering from chylothorax, chylopericardium and chylous ascites, the decision to perform TD embolization despite the presence of ascites was supported by tMRL findings of chylolymphatic reflux as the primary pathology. In patient 3 intranodal lymphangiography was performed with con- 


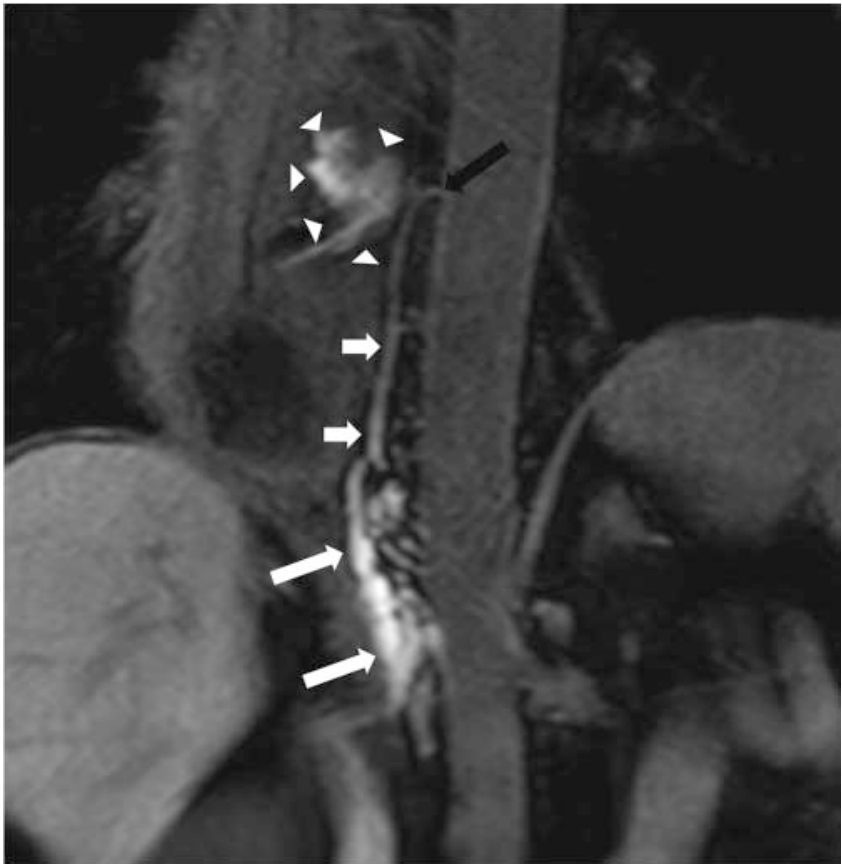

- Fig. 4 Case study 5. Coronal reconstruction of a tMRL in a patient with a postoperative chylothorax after esophagectomy demonstrates the cisterna chyli (arrows) and the lower thoracic duct (short arrows) with contrast extravasation into the right pleural cavity (arrow heads). Observe a retroaortic lymph channel draining into the thoracic duct at the site of leakage (black arrow).

- Abb.4 Fallstudie 5. Die koronare Rekonstruktion einer tMRL eines Patienten mit postoperativem Chylothorax nach Ösophagektomie zeigt die Cisterna chyli (Pfeile), den unteren Anteil des Ductus thoracicus (kurze Pfeile) und eine Kontrastmittelextravasation in die rechte Pleurahöhle (Pfeilspitzen). Zusätzlich ist eine retroaortale Lymphbahn abgrenzbar, die unmittelbar unterhalb der Leckagestelle in den Ductus thoracicus drainiert (schwarzer Pfeil).

fidence that the leakage site can be reached with ethiodized oil, providing a possible treatment option. Subsequent treatment was successful in this case. In patient 5 delineation of an aberrant retroaortic lymphatic channel led to an alteration in the extent of lymph vessel embolization to ensure successful treatment. In patient $7 \mathrm{tMRL}$ findings led to continuation of conservative therapy without attempted intervention.

All examinations were well tolerated without complications. Neither general anesthesia nor conscious sedation was necessary.

\section{Discussion}

Contrast-enhanced MR-lymphangiography with interdigital interstitial injection of a standard gadolinium-based contrast medium is an established technique for the evaluation of peripheral lymphatics of the upper and lower extremities. It has recently been used in the evaluation of peripheral edema as well as in an effort to improve the detection of lymph node metastases in the pelvis $[13,14]$. However, pedal interstitial contrast injection was so far not deemed suitable for visualization of the central lymphatics especially in adults - as contrast medium typically reaches only the pelvic lymphatics $[10,15]$. So far, contrast enhancement of the central lymphatics after interstitial contrast injection has only been reported in one case of an infant with chylothorax [16]. In the past different contrast agents have been developed to overcome this limitation (dendrimer-based gadolinium-labeled contrast medium [17]; lipophilic perfluorinated gadolinium chelates [18]). Although yielding good results in swine models, these contrast agents are not available for clinical use. Another approach utilized interstitial application of gadofosveset premixed with human albumin which led to CLS visualization in a swine model [19]. This approach requires preparation of the contrast agent/albumin mixture and has so far not been investigated in humans. Furthermore, gadofosveset is currently not available for clinical use in Germany.

Alternatively, dynamic contrast-enhanced MR-lymphangiography (DCE-MRL) $[9,10]$ that permits dynamic evaluation of lymphatic flow has shown promising results in a variety of lymphatic pathologies. However, it requires general anesthesia (or at least sedation) and time-consuming sonographically guided needle placement into inguinal lymph nodes outside the scanner room, which is associated with a risk of accidental needle dislodgment.

The results of our study demonstrate that TMRL with interstitial injection of a standard contrast agent is feasible and can be employed to visualize the CLS. In contrast to DCE-MRL, tMRT requires adequate timing of image acquisition in order to evaluate the passage of the contrast agent. Initial experiences show that image acquisition should start within a few minutes after contrast injection. In contrast to MRL of the lower extremity, in which the patient lies still during the whole examination, asking the patients to move their legs after contrast injection seems to be key to tMRL of the central lymphatics. It remains unclear why patient 6 did not show enhancement of the central lymphatics. A possible explanation may be the presence of diffuse retroperitoneal leakage, but also bilateral inguinal lymphovenous shunts as identified on conventional lymphangiography may have contributed to poor enhancement.

The most important advantage of tMRL is that it can be performed without general anesthesia or sedation. Contrast injection can be performed inside the scanner room without the need for time-consuming sonographically guided puncture. Using the water-only images of the breath-hold mDIXON sequence [11] forgoes the need for image subtraction and allows for good distinction of central lymphatics from surrounding tissue. A further advantage of our technique is the use of a commercially available extracellular contrast agent. It is important to note, however, that interstitial application is an off-label use. Infection and local reactions to the contrast medium at the injection sites are possible complications [20], but were not observed in our experience. Intramuscular injections, however, should be avoided [20].

This study is limited by its retrospective character with inherent methodological problems and by its small sample size. However, in 6/7 patients tMRL findings were confirmed by results of fluoroscopic intranodal lymphangiography. Dynamic information on lymph flow evaluated by tMRL may be limited compared to DCE-MRL with which the entire contrast medium passage can be observed. 
In conclusion, this study demonstrates the feasibility of contrast-enhanced MR imaging of the CLS by interstitial pedal injection of a standard extracellular contrast agent. tMRL is a new imaging technique that allows for assessment of pathologic conditions of central lymphatics that can be performed in clinical routine without general anesthesia.

\section{Implications for patient care}

- Interstitial transpedal MR-lymphangiography allows for minimally invasive assessment of central lymphatic anatomy and pathology in patients suffering from chylous effusions.

- tMRL can be performed in clinical routine without general anesthesia or sedation.

- It can be employed in the pre-interventional workup of lymphatic interventions, possibly influencing the therapeutic strategy.

\section{Conflict of Interest}

The authors declare that they have no conflict of interest.

\section{References}

[1] Mallick A, Bodenham AR. Disorders of the lymph circulation: their relevance to anaesthesia and intensive care. Br J Anaesth 2003; 91: 265 - 272

[2] Cope C, Salem R, Kaiser LR. Management of chylothorax by percutaneous catheterization and embolization of the thoracic duct: prospective trial. J Vasc Interv Radiol 1999; 10: 1248-1254

[3] Nadolski G], Itkin M. Thoracic duct embolization for nontraumatic chylous effusion: experience in 34 patients. Chest 2013; 143: 158-163

[4] Itkin M, Kucharczuk JC, Kwak A et al. Nonoperative thoracic duct embolization for traumatic thoracic duct leak: experience in 109 patients. J Thorac Cardiovasc Surg 2010; 139: 584- 589

[5] Schild HH, Naehle CP, Wilhelm KE et al. Lymphatic Interventions for Treatment of Chylothorax. Rofo 2015; 187: 584 - 588

[6] Clément O, Luciani A. Imaging the lymphatic system: possibilities and clinical applications. Eur Radiol 2004; 14: 1498 - 1507
[7] Dori Y. Novel Lymphatic Imaging Techniques. Tech Vasc Interv Radiol 2016; 19: 255-261

[8] Yu D-X et al. Morphological changes of the thoracic duct and accessory lymphatic channels in patients with chylothorax: Detection with unenhanced magnetic resonance imaging. Eur Radiol 2012; 23: $702-711$

[9] Dori Y, Zviman MM, Itkin M. Dynamic contrast-enhanced MR lymphangiography: feasibility study in swine. Radiology 2014; 273: 410-416

[10] Krishnamurthy R, Hernandez A, Kavuk S et al. Imaging the central conducting lymphatics: initial experience with dynamic MR lymphangiography. Radiology 2015; 274: 871 - 878

[11] Eggers H, Brendel B, Duijndam A et al. Dual-echo Dixon imaging with flexible choice of echo times. Magn Reson Med 2011; 65: 96-107

[12] Schild HH, Strassburg CP, Welz A et al. Treatment options in patients with chylothorax. Dtsch Arztebl Int 2013; 110: 819-826

[13] Hong et al. Interstitial magnetic resonance lymphography is an effective diagnostic tool for the detection of lymph node metastases in patients with cervical cancer. BMC Cancer 2012; 12: 360

[14] Lohrmann et al. Posttraumatic edema of the lower extremities: Evaluation of the lymphatic vessels with magnetic resonance lymphangiography. J Vasc Surg 2009; 49: 417-423

[15] Notohamiprodjo M, Weiss M, Baumeister RG et al. MR lymphangiography at 3.0 T: correlation with lymphoscintigraphy. Radiology 2012; 264 : $78-87$

[16] Ruehm et al. Interstitial MR lymphography with gadoterate meglumine: initial experience in humans. Radiology 2001; 220: 816-821

[17] Sena LM, Fishman SJ, Jenkins KJ et al. Magnetic resonance lymphangiography with a nano-sized gadolinium-labeled dendrimer in small and large animal models. Nanomedicine (Lond) 2010; 5: 1183-1191

[18] Staatz G, Nolte-Ernsting CC, Adam GB et al. Interstitial T1-weighted MR lymphography: Lipophilic perfluorinated gadolinium chelates in pigs. Radiology 2001; 220: 129-134

[19] Turkbey B, Kobayashi H, Hoyt RF Jr et al. Magnetic resonance lymphography of the thoracic duct after interstitial injection of gadofosveset trisodium: a pilot dosing study in a porcine model. Lymphat Res Biol 2014; 12: $32-36$

[20] Food and Drug Administration (FDA). Gadovist prescribing information. Im Internet: https://www.accessdata.fda.gov/drugsatfda_docs/label/ 2011/201277s000lbl.pdf 